AWEJ for Translation \& Literary Studies Volume, 1 Number 3, August 2017

Pp.86 -105

DOI: http://dx.doi.org/10.24093/awejtls/vol1no3.7

\title{
Literary Translation Teaching/Learning as a TRI-PHASE PROCESS: Case Study: Arabic-English and English-Arabic Translation of Novels
}

\section{Mohammed MEDIOUNI}

English Section, King Fahd School of Translation, Abdelmaleek Essaadi University, Tangier, Morocco

\begin{abstract}
The aim of the present work is to demonstrate a tri-phase method for teaching literary translation. The first pre-translation phase consists in introducing the author, his/her works, style and the text to be translated. The second phase, the translation proper, is divided into three sub-phases: (a) the identification of problems (connotative meanings, figures of speech, idioms, uncommon collocations, culture-bound items, ...), (b) the treatment of these problems by opting for the adequate procedures which should be in tune with the overall translation strategy opted for, and (c) the translation of the whole text into the target language. The final third phase is of revision and assessment. The criteria to be taken into consideration are genre-related and the focus is on the stylistic match or mismatch between the source and target texts. The present process-oriented method of literary translation is illustrated through three in-class translations of three literary texts from Arabic into English and vice versa. The targeted students are enrolled in the Master of Translation Science and Linguistics during Fall-Semester 2017 at the Faculty of Humanities at the University Abdelmalek Essaadi. The study concluded that literary translation should be taught as a creative tri-phase process throughout which students are made fully aware of the significance and impact of the strategies they opt for in order to deal with the different literary translation problems and attain the perfect stylistic equivalence so aspired for by literary translators.
\end{abstract}

Keywords: literary translation, translation procedure, translation process, translation strategy, translation problems, translation teaching

Cite as: MEDIOUNI, M. (2017). Literary Translation Teaching/Learning as a TRI-PHASE PROCESS: Case Study: Arabic-English and English-Arabic Translation of Novels. Arab World English Journal for Translation \& Literary Studies, 1(2).

DOI: http://dx.doi.org/10.24093/awejtls/vol1no3.7

Arab World English Journal for Translation \& Literary Studies

eISSN: 2550-1542 |www.awej-tls.org 